\title{
Evaluation of the implementation of centralized waiting lists for patients without a family physician and their effects across the province of Quebec
}

Mylaine Breton ${ }^{1,2^{*}}$, Astrid Brousselle ${ }^{1,2}$, Antoine Boivin $^{1,2}$, Christine Loignon ${ }^{1,2}$, Nassera Touati $^{3}$, Carl-Ardy Dubois ${ }^{4}$, Kareen Nour ${ }^{5}$, Djamal Berbiche ${ }^{1,2}$ and Danièle Roberge ${ }^{1}$

\begin{abstract}
Background: Most national and provincial commissions on healthcare services in Canada over the past decade have recommended that primary care services be strengthened in order to guarantee each citizen access to a family physician. Despite these recommendations, finding a family physician continues to be problematic. The issue of enrolment with a family physician is worrying in Canada, where nearly 21\% of the country's population reported not having a family physician in the last Commonwealth Fund survey.

To respond to this important need, centralized waiting lists have been implemented in four Canadian provinces to help 'orphan,' or unaffiliated, patients find a family physician. These organizational mechanisms are intended to better coordinate the demand for and supply of family physicians. The objectives of this study are: to assess the effects of centralized waiting lists for orphan patients (GACOs) implemented in the province of Quebec and to explain the variation among their effects by analyzing factors influencing implementation process.
\end{abstract}

Methods: This study is based on two complementary and sequential research strategies. The first (objective 1) is a quantitative longitudinal design to assess the effects of all the GACOs $(n=93)$ in Quebec using clinicaladministrative data. The second (objective 2) involves using four case studies to explain variations in effects through in-depth analysis of the various factors contributing to the observed effects. The primary source of data will be key actors involved in the GACOs. We expect to conduct around 40 semi-structured interviews.

Discussion: This will be the first study in Canada to evaluate the implementation of this innovation. It will provide an exhaustive picture of the effects of GACO implementation in Quebec and to assess their potential for generalization elsewhere in Canada. At the theoretical level, this study will produce new knowledge on the factors having the greatest influence on the implementation of primary care innovations in professional environments.

Keywords: Primary healthcare, Access, Continuity, Implementation study

\footnotetext{
* Correspondence: mylaine.breton@usherbrooke.ca

${ }^{1}$ Charles-LeMoyne Hospital Research Centre, Greenfield Park, QC J4K OA8,

Canada

${ }^{2}$ Faculty of Medicine and Health Sciences, Université de Sherbrooke-Campus

Longueuil, Longueuil, QC J4K OA8, Canada

Full list of author information is available at the end of the article
} 


\section{Background}

\section{Need for improved access to family physicians}

Several Canadian and provincial commissions on healthcare have recommended that primary care services be reinforced to guarantee every citizen access to a family physician who would, on one hand, be the primary source of most care, and on the other hand, work in a clinical setting that provides primary care that is accessible, continuous, comprehensive, and well coordinated with other levels of care [1-6]. These recommendations are based on strong evidence about the benefits of good patient management in primary care [7-9]. The literature shows that vulnerable patients are the ones who benefit most from good quality primary care $[10,11]$.

The benefits associated with having a family doctor, in terms of quality of care (e.g., preventive care activities) and care outcomes (e.g., patient satisfaction, compliance with treatment, better use of services) have been extensively documented [12-18]. The benefits are particularly clear with regard to routine care and follow-up, and somewhat less so for needs for immediate care for a minor problem [19].

Patients with chronic illnesses require regular follow-up with a primary care professional to ensure good management of their condition [20]. According to several authors, better primary care management of chronic illnesses improves health status, which decreases the probability of complications or clinical deterioration that could result in an emergency room visit or hospitalization [21-23]. Thus, the literature shows that patients with chronic illness who have no family physician are at higher risk of having poor health status [23] and of using the emergency room or being hospitalized for foreseeable and avoidable health conditions (e.g., patient with decompensated diabetes). According to a recent Canadian study, people with a chronic health problem and no family physician were 1.2 times more likely to use emergency services and 1.3 times more likely to be admitted to hospital (nonelective admission) [24]. Several countries, in fact, use rates of hospitalization for certain conditions as indicators of limited access to primary care services [21]. Emergency rooms are considered to be an inadequate and non-optimal substitute for primary care for ongoing health problems and chronic illness management [23].

Affiliation with a family physician is also considered to be a prerequisite to accessibility [13-15]. Accessibility refers to the ease or difficulty with which a person is able to establish or maintain contact with a care provider [15-17]. Accessibility and continuity of care are complementary. Accessibility is a prerequisite for relational continuity, which in turn facilitates accessibility to one's family physician or to another physician practising in the same medical clinic [25]. Continuity refers to the degree to which the healthcare services provided are carried out without interruption over time, within one or more episodes of care [26-30].

Several authors also assert that establishing a therapeutic patient-physician relationship contributes to care continuity [31,32]. Numerous studies have shown the positive effects associated with care continuity, including greater satisfaction on the part of both patients and physicians, improved compliance with treatments, reduced emergency room usage, and fewer hospitalizations [33]. As well, it is especially important for patients to be able to count on a primary care provider who knows their personal situation and is the primary person in charge of their care, an attribute which we refer to as relational continuity [8]. Relational continuity is defined by a therapeutic relationship between a patient and one or more care providers, over a span of time and for various health services, which results in providers' accumulated knowledge about the patient as well as services that are consistent with the patient's needs [8]. Several studies suggest that this relational aspect is a very high priority for patients [8,34-38]. Likewise, the Institute of Medicine considers a sustained patient-physician relationship to be a core element of primary care [39].

Despite these many recommendations, the issue of affiliation with a family physician remains a concern for Canadians, as nearly $21 \%$ of the country's population reported not having a family physician in the last Commonwealth Fund survey [40]. This situation is even more pronounced in Quebec, where nearly 29\% of the population reported not having a family physician, the worst score in Canada [40]. In addition, of the residents of Quebec without a family physician, 60\% reported that they had been unable to find a physician when they needed one [18]. Not having a family physician is especially critical for patients with the greatest needs (e.g., those who perceive themselves to be in poor health, or have one or more chronic illnesses, or have been hospitalized or undergone major surgery). For these patients presenting the greatest needs, Quebec again is in last place among the Canadian provinces in terms of patients without a family physician, as nearly $16 \%$ of these patients fall in that category [41]. This state of affairs is not unique, as vulnerable clienteles are known to experience significant difficulty in accessing primary care (inverse care law) $[11,42,43]$ and receive the fewest preventive and screening services in primary care [9]. The considerable number of patients without a family physician in Canada is therefore a major issue $[31,44]$.

\section{Research opportunity: Innovation implemented to help patients find a family physician}

In response to this problem of affiliation with a family physician, especially for more vulnerable clienteles, several Canadian provinces have set up centralized waiting lists to 
better coordinate primary care medical resources, notably in Ontario (Health Care Connect), British Columbia (A GP for Me), New Brunswick (Health Connect NB), and Quebec (GACO: Guichet d'accès aux clienteles orphelines waiting list for 'orphan' clienteles). These waiting lists are considered to be organizational innovations to improve access to family physicians and to foster continuity of care. They are used to centralize requests for family physicians in a given territory and to match orphan patients with a family physician, based on a priority scale and on the availability of primary care physicians. To our knowledge, no study has yet examined the implementation and outcomes of these new and complex organizational models, apart from one exploratory study we conducted in one region of Quebec [45].

In a context in which health resources are limited and the population's expectations are not met, it is important to assess whether these centralized waiting lists are actually effective in meeting the targeted objectives in terms of primary care accessibility and continuity. For example, in the most recent fiscal year in Quebec (2012-2013), family physicians received nearly $\$ 38$ million in bonuses for enrolling orphan patients through GACOs, not counting the other resources allocated to GACO operations, such as the nurses, secretaries, and physician coordinators working there.

\section{Study setting}

Quebec is a province of over eight million residents with a tax-based system providing universal access to medical services. Healthcare organizations, such as local community health centres (CLSC) and hospitals, receive block funding from the Ministry of Health and Social Services (MSSS), and physicians are remunerated predominantly on a fee-for-service basis. While nearly all family physicians provide medical services reimbursed by the public Medicare program, most primary healthcare practices are private rather than public enterprises.

In Quebec, 93 GACOs were set up in 2008. Each of these waiting lists is overseen by a Health and Social Services Centre (CSSS), which is responsible for the population of a given territory. The aim of this policy is to facilitate the local population's access to family physicians based on a clinical priority scale and on the availability of medical personnel in that territory.

The GACOs are managed by a secretary and a nurse, in collaboration with a local physician coordinator. Requests for registration in a GACO may come directly from patients or from referring health professionals (nurses, social workers, physicians). Once registered on a centralized waiting list, patients are assessed by the nurse, who determines their priority code according to the urgency and complexity of their healthcare needs. Patients are then enrolled with a family physician based on medical staff availability and the fields of practice of the physicians registered with the $\mathrm{GACO}$, taking into consideration as much as possible the established priorities.

A physician who accepts an orphan patient through the GACO receives a financial bonus upon the patient's first visit. This financial incentive was implemented to encourage physicians' participation in the GACOs. The amount of the incentive depends on whether the patient has been designated as vulnerable. Patients are considered vulnerable if they present one of the 19 vulnerability codes defined by Quebec's health insurance board (RAMQ) based on the presence of medical diagnoses (e.g., diabetes, chronic obstructive pulmonary disease, mental health disorder). This vulnerability code is different from the priority code determined by the nurse, but it influences that code, which establishes the patient's medical condition.

The general objective of this study is to assess the impacts of the GACOs on service accessibility and continuity and to explain variations in these impacts The specific objectives are:

1. To assess the impacts of GACOs on accessibility, continuity, and emergency room use;

2. To explain variations in the impacts by analyzing the characteristics of the GACOs and other factors influencing their implementation.

\section{Conceptual model based on implementation of a healthcare system innovation}

Analyzing the implementation of interventions such as those associated with waiting lists involves studying how, in a particular context, they produce the observed effects [46]. This type of analysis examines variations in context and in the implementation of the intervention in relation to the outcomes observed. We will base our study on a health innovations analysis model proposed by Chaudoir et al. [47] that focuses on carrying out a systematic review of the topic [47]. This model suggests paying attention to four types of factors: characteristics of the professionals involved in implementing the intervention; characteristics of the clienteles affected by the intervention; characteristics of the organization in which the intervention is implemented; and characteristics of the context. These groups of factors are described in the following paragraphs. Figure 1 shows the conceptual model on which this research is based.

The characteristics of the professionals involved in implementing the intervention refer to individual characteristics such as age, practice profile, and attitude or openmindedness toward change [48]. Certain characteristics of clienteles targeted by the intervention also appear to influence the form of the intervention implemented, as it is adapted in response to the clienteles' characteristics. 


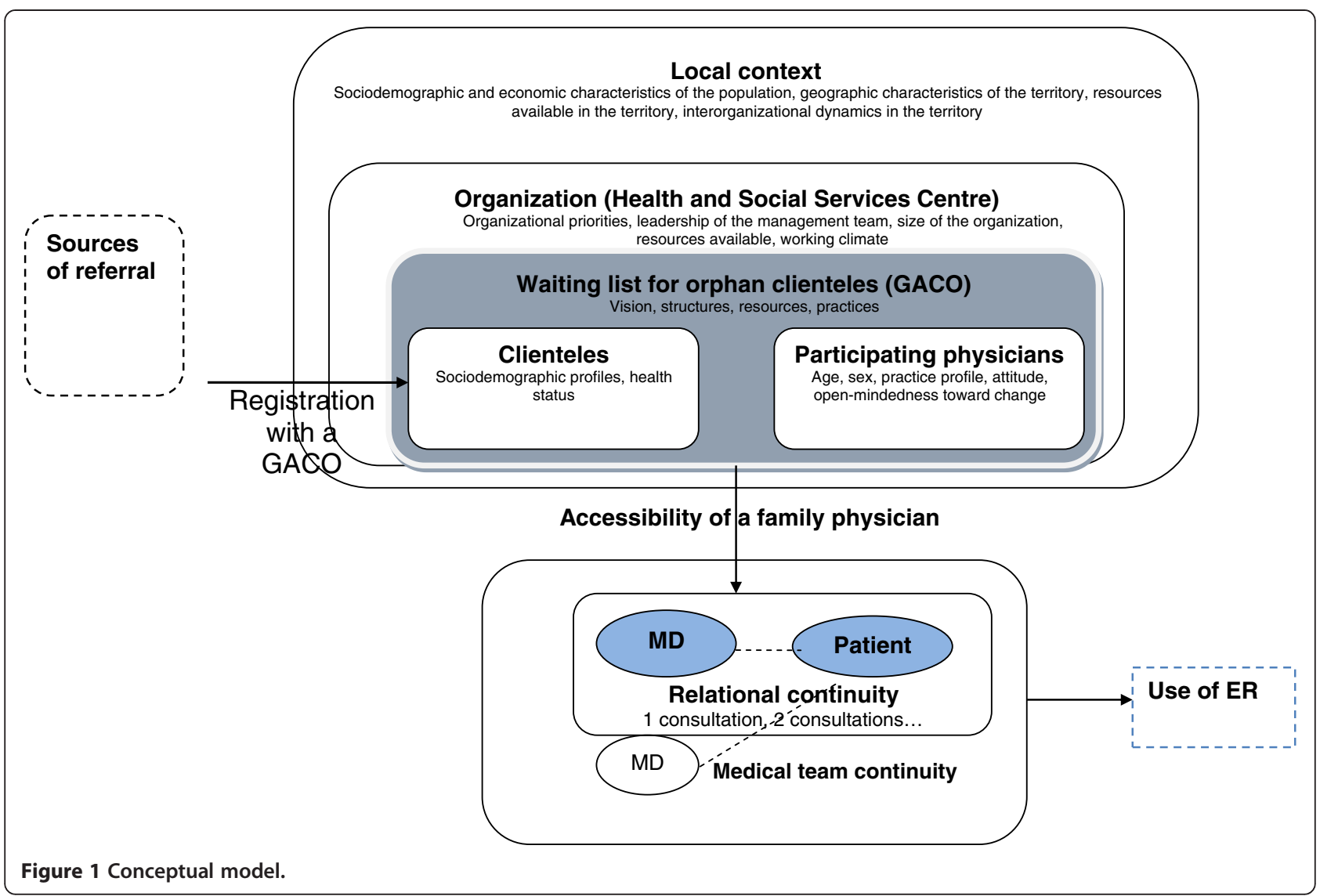

These characteristics include their sociodemographic and socioeconomic profiles as well as health status [49].

The characteristics of organizations can also influence the implementation of innovations, notably organizational priorities, the leadership of the management team, the size of the organization, the resources available, and the working climate [50-53]. Several studies have shown that one of the most important success factors for an intervention's implementation is having designated decision-makers and a governance structure to implement the intervention $[50,54]$, as well as protected funding for its operations. Likewise, the organization's values guide its various priorities, which in turn influence the allocation of resources to the intervention $[55,56]$.

Several characteristics of the local context can influence an intervention's implementation, including, in particular, the sociodemographic and socioeconomic characteristics of the population (e.g., proportion of elderly, proportion of low-income persons), the geographic characteristics of the territory (e.g., rural, urban), the resources available in the territory (e.g., number of medical clinics, presence of a hospital), and the interorganizational dynamics (e.g., collaborations among the medical clinics, and between the clinics and the CSSS) [52]. Studies have shown different effects for the same primary care models depending on the urban-rural geographic context [57,58]. Another study comparing primary care organizational models showed that the geographic context had a determining influence on medical practice [59]. Finally, there are contextual factors at the macroscopic level that also influence the implementation of innovations, such as funding models and healthcare system regulatory models, as well as the number and diversity of healthcare resources [60].

\section{Methods}

\section{Research design}

This study is based on two complementary and sequential research strategies [61]. The first strategy (objective 1) will use a longitudinal design to assess the effects of all the GACOs $(n=93)$ in Quebec. For this purpose, we will use two clinical-administrative databases. The second strategy (objective 2) will use the case study approach (multiple case study) to explain the variations in the effects through in-depth analysis of the different factors contributing to the observed effects. Case study is particularly indicated for gaining a deeper understanding of implementation processes in relation to effects [46]. 
Objective 1: Assess the impacts of GACOs on accessibility, continuity, and emergency room use

The main objective of the GACOs is to match one patient with one family physician so that the patient will be followed regularly by the family physician and will consult that physician when there is a need. To assess the effects, we will focus on: the family physician's accessibility; continuity of care; and use of emergency care. Table 1 summarizes the effects analyzed, the variables used, the definitions and reference periods, as well as the data sources. Achieving objective 1 will allow us to describe the effects of each GACO in Quebec and trace the evolution of the GACOs, and will facilitate the selection of cases for the qualitative component of the study.

\section{Variables to be studied}

\section{Accessibility to a family physician}

The creation of GACOs targeted two objectives related to family physician accessibility: to increase the number of people with family physicians, and to give access priority to vulnerable patients. As such, accessibility to a family physician will be assessed by two variables: all patients enrolled with a family physician through a GACO, and the number of vulnerable patients enrolled with a family physician through a GACO, that is, patients presenting one of the 19 vulnerability codes (e.g., diabetes, mental illness, substance use) defined by the Quebec Insurance Board (RAMQ), which is the sole payer of physicians. These variables will be analyzed according to patients' characteristics: age, gender, source of referral to the GACO (such as the ER), priority code established by the intake nurse, as well as time elapsed before enrolment with a family physician.

\section{Data sources}

We will use data from the GACOs' information system (SIGACO). This system is currently used by all GACOs in Quebec. We have privileged access to the SIGACO data through our primary partner, the Ministry of Health and Social Services (at no cost). The data are aggregated at the GACO level and anonymized. We will analyze all the data available since the year the GACOs were launched (2008) up to the most recent year for which data are available (2014). Note that we have access to the data in real time.

\section{Sample size}

Nearly 600,000 patients have been enrolled with a family physician via one of the 93 GACOs between 2008 and today, according to the SIGACO system. There has been a clear progression over time (more than 100,000 enrolments in the past six months). These numbers are high enough to obtain the statistical significance required for the analyses to be carried out.

\section{Continuity}

In this study, continuity is measured according to service utilization based on the frequency of primary care visits.

Table 1 Summary of quantitative variables analyzed, variables used, definitions, reference periods, and data sources

\begin{tabular}{|c|c|c|c|}
\hline Effects & Variables & Definition and reference period & $\begin{array}{l}\text { Data } \\
\text { sources }\end{array}$ \\
\hline \multirow[t]{2}{*}{ Accessibility } & $\begin{array}{l}\text { Patients enrolled with a family physician } \\
\text { through the GACO }\end{array}$ & $\begin{array}{l}\text { Number of patients enrolled with a family physician through } \\
\text { the GACOs per } 10,000 \text { population per year }\end{array}$ & $\begin{array}{l}\text { SIGACO, } 2011 \\
\text { census data }\end{array}$ \\
\hline & $\begin{array}{l}\text { Vulnerable patients enrolled with a family } \\
\text { physician through the GACO }\end{array}$ & $\begin{array}{l}\text { Number of vulnerable patients enrolled with a family physician } \\
\text { through the GACOs per } 10,000 \text { population per year }\end{array}$ & $\begin{array}{l}\text { SIGACO, } 2011 \\
\text { census data }\end{array}$ \\
\hline \multirow[t]{3}{*}{ Continuity } & $\begin{array}{l}\text { Visits to the family physician with whom the } \\
\text { patient was enrolled through the GACO }\end{array}$ & $\begin{array}{l}\text { Mean annual number of visits to the family physician with } \\
\text { whom the patient was enrolled through the GACO }\end{array}$ & RAMQ \\
\hline & Attendance rate & $\begin{array}{l}\text { Annual rate of primary care visits with the physician with } \\
\text { whom the patient was enrolled through the GACO compared } \\
\text { with other primary care visits to a family physician, including in } \\
\text { the ER, since the patient was enrolled with the family physician } \\
\text { through the GACO }\end{array}$ & RAMQ \\
\hline & Medical team continuity & $\begin{array}{l}\text { Annual rate of visits to the medical clinic where the physician } \\
\text { with whom the patient is enrolled practises, compared with } \\
\text { visits to other clinics, including the ER }\end{array}$ & RAMQ \\
\hline \multirow[t]{3}{*}{ ER use before/after GACO } & ER visits & $\begin{array}{l}\text { Mean annual number of visits to the ER both before and after } \\
\text { enrollment with a family physician through the GACO }\end{array}$ & RAMQ \\
\hline & Rate of ER visits & $\begin{array}{l}\text { Annual rate of visits to the ER compared with other primary care } \\
\text { visits }\end{array}$ & RAMQ \\
\hline & $\begin{array}{l}\text { Visits to the ER to see the family physician } \\
\text { with whom the patient was enrolled } \\
\text { through the GACO }\end{array}$ & $\begin{array}{l}\text { Annual rate of visits in the ER with the family physician with whom } \\
\text { the patient was enrolled through the GACO (exploratory), } \\
\text { compared with other primary care visits since the patient was } \\
\text { enrolled with that family physician through the GACO }\end{array}$ & RAMQ \\
\hline
\end{tabular}


Table 2 Details of the qualitative variables studied, their operationalization, and data sources

\begin{tabular}{|c|c|c|}
\hline Physician characteristics & CSSS characteristics & Local context \\
\hline \multirow[t]{4}{*}{$\begin{array}{l}\text { Sociodemographic profile (age, gender), practice } \\
\text { profiles, type of primary care organization, proportion } \\
\text { of time devoted to primary care, attitudes toward } \\
\text { GACO, motivation for participation }\end{array}$} & Population focus vs. clientele focus & $\begin{array}{l}\text { Integration of the population focus (CSSS leadership } \\
\text { and coordination). Sociodemographic characteristics } \\
\text { of the population (proportion of elderly persons, } \\
\text { proportion of low-income persons/households, etc.), } \\
\text { geographic characteristics of the territory (rural, } \\
\text { urban, semi-urban) }\end{array}$ \\
\hline & $\begin{array}{l}\text { Leadership and governance: CSSS } \\
\text { management team, role of the local family } \\
\text { medicine department, organizational } \\
\text { priorities }\end{array}$ & $\begin{array}{l}\text { Territorial and interorganizational dynamics } \\
\text { (collaboration among organizations) }\end{array}$ \\
\hline & $\begin{array}{l}\text { Resources: CSSS size, number of } \\
\text { organizations making up the CSSS }\end{array}$ & $\begin{array}{l}\text { Professional resources in the territory (number of } \\
\text { family physicians, number of specialists), characteristics } \\
\text { of the professionals in the territory (level of training, } \\
\text { types of professionals), number of primary care } \\
\text { organizations and prevalent organizational models }\end{array}$ \\
\hline & $\begin{array}{l}\text { Dynamics: Collaboration agreements with } \\
\text { clinics in the territory, support for patient } \\
\text { management }\end{array}$ & \\
\hline
\end{tabular}

This strategy will allow us to assess the 'longitudinal' nature of the phenomenon, and is often used in primary care studies [62]. Continuity will be assessed on two dimensions: relational continuity and the continuity of the medical team.

Relational continuity is used to assess encounters between physicians and patients. It will be evaluated using two variables: patients' annual visits to the family physician with whom they were enrolled through the GACO, and attendance rates (usual provider of care) [63]. The variables will be analyzed over a two-year period beginning from the time when the patient was first enrolled with the family physician through the GACO. These variables are based on the literature, which shows that patients will prefer to consult the primary care physician who is following them. Medical team continuity will be used to assess visits to other physicians who are in the same primary care organization in which the patient's assigned physician practises.

These variables will be analyzed according to patients' characteristics: age, gender, and a comorbidity index that takes into account both the number of comorbid conditions and their severity. In Quebec, physicians are remunerated based on information provided for each patient visit: diagnostic codes and medical acts codes related to each visit are thus compiled, making it possible to determine whether the patient had a significant pathology.

\section{Data collection}

To assess effects on continuity, we will us a RAMQ database containing all the billing codes for medical acts. Since a billing code is issued by the RAMQ for every patient referred through the GACOs, it will be easy to obtain the database covering all patient enrolled with a family physician through the GACOs.

\section{Sample size}

The RAMQ database contains all patients enrolled with a family physician through the GACOs since their creation in 2008. These numbers are sufficiently high to obtain the statistical significance required for the analyses to be carried out. We will analyze all the data available from the year the GACOs were launched up to the year for which we have the most recent data from the RAMQ (2014).

\section{Emergency room use}

Emergency room utilization is often considered to be an inadequate substitute for primary care services, and as such, can be used to assess indirectly weaknesses in accessibility and continuity. Several studies seem to indicate that people with a family physician make less use of emergency room services $[23,27,64]$. Our aim is to assess the potential impact on emergency room use of people having become enrolled with a family physician through the GACOs. One of the variables used for this will be the average number of annual visits to the ER before and after the GACO enrolment, as well as the ratio of annual visits to the ER versus other primary care visits. As patients can see several physicians in one ER visit (RAMQ billing code), we will consider one visit to the ER per 24 hours [65]. Lastly, we intend to analyze the proportion of ER visits carried out with the family physician to whom the patient was enrolled through the GACOs. Our aim is to analyze whether, in certain contexts, particularly in rural areas, the ER is the setting used to see one's family physician [66]. This variable will be analyzed for exploratory purposes. All variables related to ER use will be analyzed according to the same patient characteristics as used for the continuity variables, i.e., age and gender. 


\section{Data collection}

We will use the same RAMQ database for this component as for the continuity analysis.

\section{Analyses}

First, we will prepare a profile of the effects on an annual basis for each GACO in Quebec. Then we will compare the annual effects among the GACOs to identify those with the best and worst outcomes. Finally, we will compare the GACO profiles over time and among themselves to analyze the impacts of policy changes on GACO outcomes, including changes to financial incentives for family physicians. For the effects on accessibility, the variables will be analyzed using linear regressions with repeated measures. For the effects on continuity, logistical or linear regressions will be performed depending on the nature of the data (continuous or categorical). Finally, for ER use, repeated measures ANOVA analysis will be performed. For each of the variables, sub-analyses will be performed according to the different patient characteristics (age, gender, principal diagnosis). We will use SAS 9.3 for all the analyses.

\section{Objective 2: Explain variations in the impacts by analyzing the characteristics of the GACOs and other factors influencing their implementation}

Our aim is to understand better what factors explain the variations observed among the GACOs.

\section{Case selection}

We will analyze four Quebec cases in depth. The cases will be selected to ensure we have contrasted cases in terms of effects. We intend to analyze two cases among those with the best outcomes on all the indicators analyzed in part one of the study (accessibility) and two cases at the other extreme for these indicators.

\section{Variables to be studied}

We will characterize the GACOs under study by describing their visions and the resources, structures, and practices put in place. We will analyze four types of factors that have influenced the implementation of GACOs and the results obtained. Our analysis will look at: the characteristics of the physicians participating in the GACOs; the characteristics of patients on the GACO waiting lists and those of the patients enrolled with a family physician through GACOs; the characteristics of the CSSSs in which the GACOs have been implemented; and the characteristics of the local context. Table 2 presents the details of the variables to be studied, how they will be operationalized, and the data sources.

\section{Data sources}

The primary sources of data will be the key actors involved and the grey literature. Our data collection strategy will involve individual semi-structured interviews. First, we will meet the key actors involved in the GACOs' operations $(n=5 /$ case; total $n=20)$, including a nurse, the medical coordinator, a secretary, a manager, and the local head of the regional family medicine department. These interviews will enable us to better describe the characteristics of the GACOs (vision, structures, resources, tools) and the different factors influencing their implementation (family physicians, patients, CSSS, local context). Second, we will interview physicians registered with GACOs $(n=4 /$ case; total $n=16)$. The physicians will be identified with the help of the local medical coordinator. These interviews will provide a better understanding of the factors that facilitate and impede physicians' participation in GACOs. All interviews will be audio-recorded and subsequently transcribed verbatim by a professional transcriptionist.

\section{Analysis}

The research technician will code every interview. The data will be coded using NVivo (QSR) software, such that, in each transcript, the different points addressed in the interviews will be labelled. We have established a summary list of initial codes based on our conceptual model (Table 2). This list shows the different characteristics of the GACO models that have been implemented and the factors that might influence them. This list will be modified and enhanced over the course of the analyses. Coding will be controlled using a double-coding technique. Coding will be done primarily by the research technician and one researcher (Breton), who will code the first interviews in parallel and independently and then will compare their results. Where there are differences, they will clarify these, refine the codes, and repeat the coding. This process will be repeated until we obtain inter-coder agreement of more than 90\% [54].

We will start with an intra-case analysis. We will analyze the coded material and the effects variables and will synthesize the results using tables and matrices [54]. These will summarize the data obtained for each case being studied. The matrices will present the results by grouping together the codes according to the different themes proposed in our conceptual framework and any new themes that might emerge during the analysis. From these tables and matrices, for each case studied, we will prepare a 'thematic network analysis', which consists of identifying the relationships among the different dominant themes (organizing themes) and the characteristics that make them up (basic themes) using graphic representations [67]. We will use this analytical approach to gain a better understanding of the relationships among 
the different factors and the observed effects. We will then use this material to perform a cross-sectional inter-case analysis. We will analyze the similarities and differences among the four case studies, as illustrated by the thematic network analysis, and will draw out the key lessons. This analysis strategy will help us in developing a set of recommendations regarding GACO models that perform well and less well (in relation to outcomes), their key components, and the environmental factors that facilitate or impede implementation. We will prepare a synthesis report on the key lessons that can facilitate better implementation of GACOs in different implementation contexts.

The study has been approved by the Research Ethics Board of the Centre hospitalier universitaire de Sherbrooke (ref. number CHUS14-091).

\section{Study validity}

\section{Construct validity}

This is ensured by a detailed conceptual model that identifies the different variables to be studied [68]. These variables are based on an exhaustive literature review and on results obtained and observations made during the monitoring project.

\section{Internal validity}

This will be ensured by using an analytical framework, doing systematic coding, and rigorously organizing the data, as well as by triangulating the qualitative data through analysis of different perspectives [69]. Analysis of contrasting cases will also reinforce internal validity. For the quantitative component, a temporal bias could affect the results, as patients' health status could change over time. However, several indicators deal with proportions of numbers of visits. Also, the same patients are followed over time, which will make it possible to control for patient characteristics.

\section{External validity}

Using multiple case studies with contrasted representations of implementation contexts will reinforce external validity [68]. It will also be reinforced by holding discussion sessions between the research team and the pan-Canadian committee to better understand the factors producing the effects in the different implementation contexts.

\section{Fidelity}

The detailed descriptions at each stage of our multiple case study will ensure fidelity, especially given that the procedure followed for each activity will be described and presented in a research report.

\section{Discussion}

To our knowledge, no research has yet been done on the implementation and effects of these new and complex organizational models, apart from one exploratory study we conducted in one region of Quebec [45]. The study we propose will help to fill in these gaps and respond to these questions. This study will enable us to learn about the mechanisms by which the effects are produced, including several aspects related to the implementation of waiting lists: the phenomenon of registering and selecting clienteles, the roles of professionals in the processing of requests, the influence of incentives for physicians' participation in waiting lists. This project will contribute not only to the body of scientific knowledge on the organization of primary care innovations, but will also be very useful to decision-makers and clinicians in the different Canadian provinces by providing a better understanding of the issues and promising strategies for implementing waiting lists in Quebec and elsewhere in Canada.

\section{Abbreviations \\ MSSS: Ministry of Health and Social Services; CSSS: Health and social services centre; RAMQ: Quebec Health Insurance Board; GACO: Guichet d'accès aux clienteles orphelines (waiting list for 'orphan' clienteles).}

\section{Competing interests}

The authors declare that they have no competing interests.

\section{Authors' contributions}

$\mathrm{MB}$ led the coordination and the conceptualization of the study. MB, ABrousselle and DR wrote the first draft, ABoivin, CL, NT, CAD, KN and DB critically reviewed it and provided comments to improve the manuscript. All authors have read and commented on the final manuscript.

\section{Acknowledgements}

This study is funded by the Fonds de recherche du Québec - Santé (FRQ-S Grant \#28974) and the Agence de la santé et des services sociaux de la Montérégie, for which MB is the principal investigator. We thank all the decision-makers involved in this research project: François Dubé, Véronique Bernard-Laliberté, Serge Dulude, Denise Trudel, Geneviève Ménard, Danièle Francoeur, Louise Quesnel, Jean Rodrigue.

\section{Author details}

'Charles-LeMoyne Hospital Research Centre, Greenfield Park, QC J4K 0A8, Canada. ${ }^{2}$ Faculty of Medicine and Health Sciences, Université de Sherbrooke-Campus Longueuil, Longueuil, QC J4K 0A8, Canada. ${ }^{3}$ École Nationale d'Administration Publique, Montreal, QC G1K 9E5, Canada. ${ }^{4}$ Faculty of Nursing, University of Montreal, Montreal, QC H3C 3J7, Canada. ${ }^{5}$ Montérégie Regional Department of Public Health, Longueil, QC J4K 2M3, Canada.

Received: 4 July 2014 Accepted: 25 August 2014

Published: 4 September 2014

\section{References}

1. Romanow RJ: Building on Values: The Future of Health Care in Canada. Final Report, Commission on the Future of Health Care in Canada. Ottawa: Government of Canada; 2002.

2. Clair M: Les solutions émergentes: Rapport et recommandations. Québec: Commission d'étude sur les services de santé et les services sociaux; 2000.

3. Mazankowski D: A Framework for Reform: Report of the Premier's Advisory Council on Health. Edmonton: Government of Alberta; 2011.

4. Health Services Restructuring Commission: Looking Back, Looking Forward: The Ontario Health Services Restructuring Commission (1996-2000). Toronto: Government of Ontario; 2000

5. Commission on Medicare: Caring for Medicare: Sustaining a Quality System. Regina: Saskatchewan Health; 2001. 
6. Kirby J, LeBreton M: The Health of Canadians: The Federal Role. Volume 6: Recommendations for Reform. Ottawa: Standing Senate Committee on Social Affairs, Science and Technology; 2002

7. Xu KT: Usual source of care in preventive service use: a regular doctor versus a regular site. Health Serv Res 2002, 37(6):1509-1529.

8. Burge F, Haggerty J, Pineault R, Beaulieu MD, Lévesque JF, Beaulieu C, Santor DA: Relational continuity from the patient perspective: comparison of primary healthcare evaluation instruments. Healthc Policy 2011, 7:124-138.

9. Blewett LA, Ziegenfuss J, Davern ME: Local access to care programs (LACPs): new developments in the access to care for the uninsured. Milbank Q 2008, 86(3):459-479.

10. Loignon C, Allison P, Landry A, Richard L, Brodeur J, Bedos C: Providing humanistic care: dentists' experience in deprived areas. J Dent Res 2010, 89(9):991-995.

11. Loignon C, Haggerty JL, Fortin M, Bedos CP, Allen D, Barbeau D: Physicians' social competence in the provision of care to persons living in poverty: research protocol. BMC Health Serv Res 2010, 10:79.

12. Bindman AB, Grumbach K, Osmond D, Komaromy M, Vranizan K, Lurie N Billings J, Stewart A: Preventable hospitalizations and access to health care. JAMA 1995, 274(4):305-311.

13. Jatrana $S$, Crampton $P$, Richardson K: Continuity of care with general practioners in New Zealand: results from So-FIE-Primary Care. N Z Med J 2011, 124(1329):286-296.

14. Jatrana S, Crampton P: Affiliation with a primary care provider in New Zealand: who is, who isn't. Health Policy 2009, 91(3):286-296.

15. Frenck JA: The concept and measure of accessibilty. In Health Services Research: An Anthology. Edited by White KL, Frenck JA, Ordóñez C, Paganini JM, Starfield B. Washington: Pan American Health Organization; 1992:842-855.

16. Haggerty J, Lévesque JF, Santor DA, Burge F, Beaulieu C, Bouharaoui F Beaulieu MD, Pineault R: Accessibility from the patient perspective: comparison of primary healthcare evaluation instruments. Health Policy 2011, 7:94-107.

17. Lévesque JF, Haggerty JL, Burge F, Beaulieu MD, Gass D, Pineault R, Santor DA: Canadian experts' views on the importance of attributes within professional and community-oriented primary healthcare models. Health Policy 2011, 7:21-30.

18. Haggerty J, Pineault R, Beaulieu MD, Brunelle Y, Goulet F, Rodrigue J, Gauthier J: Accessibility and Continuity of Primary Care in Quebec. Ottawa: Canadian Health Services Research Foundation; 2004

19. Kapetanakis C, Ouellet $D$, Pineault R: Besoins et difficultés d'accès aux services de premier contact. Montreal: Institut national de santé publique, Agence de la santé et des services sociaux de Montréal, Direction de la santé publique Montréal; 2003.

20. Crooks VA, Agarwal G, Harrison A: Chronically ill Canadians' experiences of being unattached to a family doctor: a qualitative study of marginalized patients in British Columbia. BMC Fam Pract 2012, 13:69.

21. Brown AD, Goldacre MJ, Hicks N, Rourke JT, McMurty RY, Brown JD, Anderson GM: Hospitalization for ambulatory care-sensitive conditions: a method for comparative access and quality studies using routinely collected statistics. Can J Public Health 2001, 92(2):155-159.

22. Weingarten SR, Henning JM, Badamgarav E, Knight K, Hasselblad V, Gano A $\mathrm{Jr}$, Ofman JJ: Interventions used in disease management programmes for patients with chronic illness-which ones work? Meta-analysis of published reports. BMJ 2002, 325(7370):925

23. McCusker J, Roberge D, Lévesque JF, Ciampi A, Vadeboncoeur A, Larouche D, Sanche S: Emergency department visits and primary care among adults with chronic conditions. Med Care 2010, 48(11):972-980.

24. Glazier RH, Moineddin R, Agha MM, Zagorski B, Hall R, Manuel DG, Sibley LM, Koop A: The Impact of Not Having a Primary Care Physician Among People with Chronic Conditions. ICES Investigative Report. Toronto: Institute for Clinical Investigative Sciences; 2008.

25. Levesque JF, Harris MF, Russell G: Patient-centred access to health care: conceptualising access at the interface of health systems and populations. Int J Equity Health 2013, 12:18-26.

26. Salisbury C, Sampson F, Ridd M, Montgomery AA: How should continuity of care in primary health care be assessed? Br J Gen Pract 2009, 59(561):e134-e141.

27. lonescu-lttu R, McCusker J, Ciampi A, Vadeboncoeur AM, Roberge D, Larouche D, Verdon J, Pineault R: Continuity of primary care and emergency department utilization among elderly people. CMAJ 2007, 177(11):1362-1368.
28. Freeman GK, Olesen F, Hjortdahl P: Continuity of care: an essential element of modern general practice? Fam Pract 2003, 20:623-627.

29. Haggerty JL, Reid RJ, Freeman GK, Starfield BH, Adair CE, McKendry R: Continuity of care: a multidisciplinary review. BMJ 2003, 22(327):1219-1221.

30. Reid R, Haggerty J, McKendry R: Defusing the Confusion: Concepts and Measures of Continuity of Healthcare. Ottawa: Canadian Health Services Research Foundation; 2002

31. Schoen C, Osborn R, Huynh PT, Doty M, Davis K, Zapert K, Peugh J: Primary care and health system performance: adults' experiences in five countries. Health Aff (Millwood) 2004, 23:487-503.

32. Hay C, Pacey M, Bains N: Understanding the unattached population in Ontario: evidence from the Primary Care Access Survey (PCAS). Healthc Policy 2010, 6(2):33-47.

33. Nutting PA, Goodwin MA, Flocke SA, Zyzanski SJ, Stange KC: Continuity of primary care: to whom does it matter and when? Ann Fam Med 2003, 1(3):149-155.

34. Little P, Everitt H, Williamson I, Warner G, Moore M, Gould C, Ferrier K, Payne S: Preferences of patients for patient centred approach to consultation in primary care: observational study. BMJ 2001, 322:468.

35. Turner D, Tarrant C, Windridge K, Bryan S, Boulton M, Freeman G, Baker R: Do patients value continuity of care in general practice? An investigation using stated preference discrete choice experiments. J Health Serv Res Policy 2007, 12(3):132-137.

36. Cheraghi-Sohi S, Hole AR, Mead N, McDonald R, Whalley D, Bower P, Roland M: What patients want from primary care consultations: a discrete choice experiment to identify patients' priorities. Ann Fam Med 2008, 6(2):107-115.

37. Sualtz JW: Defining and measuring interpersonal continuity of care. Ann Fam Med 2003, 1(3):134-143.

38. Gulliford M, Naithani S, Morgan M: What is continuity of care? J Health Serv Res Policy 2006, 11(4):248-250.

39. Committee on the Quality of Health Care in America: Crossing the Quality Chasm: a New Health System for the 21st Century. Washington, DC: Institute of Medicine; 2001

40. Commissaire à la santé et au bien-être: L'expérience de soins de la population: Le Québec comparé. Résultats de l'enquête internationale du Commonwealth Fund de 2010 auprès de la population de 18 ans et plus. Québec: Commissaire à la santé et au bien-être du Québec; 2010.

41. Commissaire à la santé et au bien-être: L'expérience de soins des personnes présentant les plus grands besoins de santé : Le Québec comparé. Résultats de l'enquête internationale sur les politiques de santé du Commonwealth Fund de 2011. Québec: Commissaire à la santé et au bien-être du Québec; 2011

42. Mercer SW, Watt G: The inverse care law: clinical primary care encounters in deprived and affluent areas of Scotland. Ann Fam Med 2007, 5:503-510.

43. Chafe R, Laupacis A, Levinson W: Accepting new patients: what does the public think about Ontario's policy? Can Fam Physician 2011, 57(2):e68-e73.

44. Schoen C, Osborn R, Doty MM, Squires D, Peugh J, Applebaum S: A survey of primary care physicians in eleven countries, 2009: perspectives on care, costs, and experiences. Health Aff (Millwood) 2009, 28(6):w1171-w1183.

45. Breton M, Ricard J, Walter N: Connecting orphan patients with family physicians: differences among Quebec's access registries. Can Fam Physician 2012, 58(9):921-922

46. Champagne F, Brousselle A, Hartz Z, Contandriopoulos A, Denis J: L'analyse de l'implantation. In L'évaluation: concepts et méthodes. Edited by Brousselle A, Champagne F, Contandriopoulos A, Hartz Z. Montreal: Les Presses de I'Université de Montréal; 2011:237-273.

47. Chaudoir SR, Dugan AG, Barr CHI: Measuring factors affecting implementation of health innovations: a systematic review of structural, organizational, provider, patient, and innovation level measures. Implement Sci 2013, 8:22.

48. Greenhalgh T, Robert G, Macfarlane F, Bate P, Kyriakidou O: Diffusion of innovations in service organizations: systematic review and recommendations. Milbank Q 2004, 82(4):581-629.

49. Damschroder L, Aron D, Keith R, Kirsh S, Alexander JA, Lowery JC: Fostering implementation of health services research findings into practice: a consolidated framework for advancing implementation science. Implement Sci 2009, 4:50-64.

50. Pomey MP, Forest PG, Sanmartin C, Decoster C, Clavel N, Warren E, Drew M, Noseworthy T: Toward systematic reviews to understand the determinants of wait time management success to help decision-makers and managers better manage wait times. Implement Sci 2013, 8:61. 
51. Pomey MP, Forest PG, Sanmartin C, De Coster C, Drew M: Wait time management strategies for scheduled care: what makes them succeed? Healthc Policy 2010, 5(3):66-81.

52. Hogg W, Rowan M, Russell G, Geneau R, Muldoon L: Framework for primary care organizations: the importance of a structural domain. Int $\mathrm{J}$ Qual Health Care 2008, 20(5):308-313.

53. Miles MB, Huberman AM: Qualitative Data Analysis: An Expanded Sourcebook. 2nd edition. Thousand Oaks: Sage Publications; 1994.

54. Maddison P, Jones J, Breslin A, Barton C, Fleur J, Lewis R, McSweeney L, Norgain C, Smith S, Thomas C, Tillson C: Improved access and targeting of musculoskeletal services in northwest Wales: targeted early access to musculoskeletal services (TEAMS) programme. BMJ 2004, 329(7478):1325-1327.

55. Hroscikoski MC, Solberg LI, Sperl-Hillen J, Harper PG, McGrail MP, Crabtree BF: Challenges of change: a qualitative study of chronic care model implementation. Ann Fam Med 2006, 4(4):317-326.

56. Russell G, Thille P, Hogg W, Lemelin J: Beyond fighting fires and chasing tails? Chronic illness care plans in Ontario. Canada Ann Fam Med 2008, 6(2):146-153.

57. Lamarche PA, Beaulieu MD, Pineault R, Contandriopoulos AP, Denis JL, Haggerty J: Choices for Change: The Path for Restructuring Primary Healthcare Services in Canada. Ottawa: Canadian Health Services Research Foundation; 2003.

58. Haggerty $\mathrm{J}$, Roberge $\mathrm{D}$, Pineault $\mathrm{R}$, Larouche $\mathrm{D}$, Touati $\mathrm{N}$ : Features of primary healthcare clinics associated with patients' utilization of emergency rooms: urban-rural differences. Healthc Policy 2007, 3(2):72-85.

59. Fernández LA, Martin JM, Del Castillo JD, Gaspar OS, Millán JI, Lozano MJ, Keenoy ED: Sources of influence on medical practice. J Epidemiol Community Health 2000, 54(8):623-630.

60. Mendel P, Meredith LS, Schoenbaum M, Sherbourne CD, Wells KB: Interventions in organizational and community context: a framework for building evidence on dissemination and implementation in health services research. Adm Policy Ment Health 2008, 35:21-37.

61. Creswell JW, Plano Clark VL: Designing and Conducting Mixed Methods Research. 2nd edition. Los Angeles, CA: Sage Publications; 2011.

62. Provost S, Pineault R, Couture A, Borges Da Silva R, Lemoine O, Tousignant P: Affiliation à un médecin de famille: Une mesure à partir des banques de données médico-administratives. Montreal: Institut national de santé publique; 2013.

63. Breslau N, Reeb KG: Continuity of care in a university-based practice. J Med Educ 1975, 50(10):965-969.

64. Sarver JH, Cydulka RK, Baker DW: Usual source of care and nonurgent emergency department use. Acad Emerg Med 2002, 9(9):916-923.

65. Belzile E, Sanche S, McCusker J, Vadeboncoueur A, Ciampi A, Lévesque JF: Création d'une mesure de visite au département d'urgence à partir des données administratives du Québec. Rapport technique. Montreal: St. Mary's Hospital Research Centre; 2011.

66. Da Silva RB, Pineault R: Impact of physician distribution policies on primary care practices in rural Quebec. Can J Rural Med 2012, 17(3):92-98.

67. Attride-Stirling J: Thematic networks: an analytic tool for qualitative research. Qual Res 2001, 1(3):385-405

68. Yin RK: Case Study Research: Design and Methods. 4th edition. Thousand Oaks, CA: Sage Publications; 2009.

69. Contandriopoulos A, Champagne F, Potvin L, Denis J, Boyle P (Eds): Savoir préparer une recherche: la définir, la structurer, la financer. Montréal: Les Presses de l'Université de Montréal; 1990.

doi:10.1186/s13012-014-0117-9

Cite this article as: Breton et al: Evaluation of the implementation of centralized waiting lists for patients without a family physician and their effects across the province of Quebec. Implementation Science 2014 9:117.

\section{Submit your next manuscript to BioMed Central and take full advantage of:}

- Convenient online submission

- Thorough peer review

- No space constraints or color figure charges

- Immediate publication on acceptance

- Inclusion in PubMed, CAS, Scopus and Google Scholar

- Research which is freely available for redistribution

Submit your manuscript at www.biomedcentral.com/submit
Ciomed Central 